Article

\title{
Non-Contact Measurement of the Surface Displacement of a Slope Based on a Smart Binocular Vision System
}

\author{
Leping He ${ }^{1}$, Jie Tan ${ }^{1}$, Qijun Hu ${ }^{1, *}$, Songsheng He ${ }^{1}$, Qijie Cai ${ }^{2}$, Yutong Fu ${ }^{1}$ and Shuang Tang ${ }^{1}$ \\ 1 School of Civil Engineering and Architecture, Southwest Petroleum University, Chengdu 610500, China; \\ 201231010028@swpu.edu.cn (L.H.); 201722000532@stu.swpu.edu.cn (J.T.); sheng583786602@163.com (S.H.); \\ 201622000204@stu.swpu.edu.cn (Y.F.); 201722000537@stu.swpu.edu.cn (S.T.) \\ 2 School of Transportation and Logistics, Southwest Jiaotong University, Chengdu 610031, China; \\ caiqijieswjt@my.swjtu.edu.cn \\ * Correspondence: huqijunswpu@163.com; Tel.: +86-130-7283-2168
}

Received: 14 July 2018; Accepted: 25 August 2018; Published: 31 August 2018

\begin{abstract}
The paper presents an intelligent real-time slope surface deformation monitoring system based on binocular stereo-vision. To adapt the system to field slope monitoring, a design scheme of concentric marking point is proposed. Techniques including Zernike moment edge extraction, the least squares method, and k-means clustering are used to design a sub-pixel precision localization method for marker images. This study is mostly focused on the tracking accuracy of objects in multi-frame images obtained from a binocular camera. For this purpose, the Upsampled Cross Correlation (UCC) sub-pixel template matching technique is employed to improve the spatial-temporal contextual (STC) target-tracking algorithm. As a result, the tracking accuracy is improved to the sub-pixel level while keeping the STC tracking algorithm at high speed. The performance of the proposed vision monitoring system has been well verified through laboratory tests.
\end{abstract}

Keywords: slope monitoring; surface deformation; binocular vision; subpixel resolution; user defined target

\section{Introduction}

Landslide disasters cause serious damage to human life and the economy. Surface deformation is an important basis for assessing the safety status of a slope. At present, slope surface deformation monitoring methods are of five main classes: geodetic methods, global positioning system (GPS) technology, three-dimensional (3D) laser scanning, interferometric synthetic-aperture radar (INSAR) technology, and digital photogrammetry. Geodetic measurement [1] is a traditional monitoring method; however, owing to a low observation frequency and low intelligence, it is difficult to obtain monitoring data that has spatial-temporal continuity. GPS [2] has a high degree of intelligence and can achieve full-time monitoring; however, its target setting is limited, that is, no obstacles are allowed within a range of $15^{\circ}$ around the elevation angle of the station in most cases [3]. Both 3D laser scanning [4] and INSAR technology [5] are free at the selection of the marker points, but are costly and difficult to apply to slopes covered with vegetation.

In view of the above problems, owing to their non-contact and cost-effective features, vision-based digital photogrammetry systems have been studied extensively in recent years. The method converts the image coordinates into spatial coordinates by tracking the target image, and obtains the structural deformation information [6]. In practice, the most prominent limitation of visual sensor systems is the measurement accuracy. The main factors affecting this accuracy are (1) marker points and 
(2) target tracking and positioning. On the one hand, some scholars have used natural marking points when applying machine vision technology to structural deformation monitoring. For instance, Yoon et al. [7] use the Harris corner detection algorithm to extract the feature points of the specified area of a structure. Khuc et al. [8] use a Hessian matrix $[9,10]$ to extract the key points on a steel beam. At the same time, others directly use obvious features such as a light-emitting diode lamps [11] and structural bumps [12-14] as the monitoring markers. On the other hand, target markers with specially designed features, such as a circle [15-17], a checkerboard [18-20], or a random pattern [21], have also been widely used. The position of a feature can be detected and then transformed into the coordinate information. Considering the insufficient feature points of a large slope, it is necessary to artificially set the landmarks to achieve a measurement. The positioning accuracy of the landmarks greatly determines the accuracy of the monitoring results. Common image positioning methods include the least squares fitting method [22], grey weighted centroid method [23], SUSAN algorithm [24], and Hough transform method [25]. Therefore, the authors propose a concentric marker and positioning method that adapts to the visual monitoring system applied. Even if the slope is covered by vegetation, high-precision positioning of the measuring point can be achieved.

For continuous intelligent monitoring, consumer-level cameras can be used to track and locate the landmarks in each frame. The current tracking algorithms mainly include KLT [7,26], CN [27], KCF [28], ODFS [29], and spatial-temporal contextual (STC) [30,31]. However, existing target-tracking algorithms have mostly been studied with regard to their intelligent stability, whereas a few have been studied for their positioning accuracy. To meet the accuracy requirements of deformation monitoring, scholars usually use template matching technology to obtain high-precision monitoring results. A variety of methods are applied to template matching for vision sensors including digital image correlation, pattern matching, optical flow, sub-pixel Hough transforms, random sample consensus, edge detection, sum of squared differences, scale-invariant feature transform, and the orientation code matching(OCM) [14,16,20,32-35]. Based on the OCM template matching algorithm, Feng et al. [14] demonstrated the high accuracy of the vision sensor for dense full-field displacement measurements through experimental results. Javh et al. [34] showed a sub-pixel displacement resolution of less than thousandths of a pixel by a simplified gradient-based optical flow method under laboratory conditions. However, these methods are limited in obtaining the three-dimensional deformation of a structure. It is generally known that slope surface monitoring requires three-dimensional information. Based on binocular stereoscopic vision measurement technology, to overcome the original frame-by-frame selection method for targets, we combine the temporal-spatial contextual visual tracking algorithm (STC) [31] with sub-pixel image registration technology [36], and improve the tracking accuracy to the sub-pixel level while maintaining the high speed STC algorithm to achieve real-time monitoring.

In this paper, to realise the intelligent real-time monitoring of a slope surface deformation, binocular stereo-vision measurement technology is introduced into the monitoring of the slope surface deformation, and the designs of concentric landmark points and high-precision image positioning methods are described. At the same time, the existing tracking technology is improved to achieve high-precision target tracking and spatial positioning. Finally, laboratory tests conducted to verify the validity and accuracy of the proposed method are detailed.

\section{Proposed Smart Binocular Vision System}

\subsection{Overview}

A binocular vision based displacement measurement system is typically composed of hardware and software (see Figure 1). The hardware components consist of a commercial binocular camera, a computer for storing and processing data, and a custom target. The binocular camera has a zoom lens from $4 \mathrm{~mm}$ to $12 \mathrm{~mm}$, with a maximum resolution of $2560 \times 960$ pixels, and an adjustable acquisition frame rate up to $60 \mathrm{fps}$. The stereo baseline can be adjusted from $4.5 \mathrm{~cm}$ to $18 \mathrm{~cm}$, and the field of view of the camera is from $29^{\circ}$ to $78^{\circ}$. The vision system was worked on a laptop (Lenovo Xiaoxinchao500, 
Beijing, China) with an Intel i7-7500U processor with 4 GB of RAM and a mechanical hard disk drive. The movements of a target can be recorded and tracked by the camera and synchronously transferred to the computer, where the displacement is calculated using object centre location algorithms and coordinate transformations.

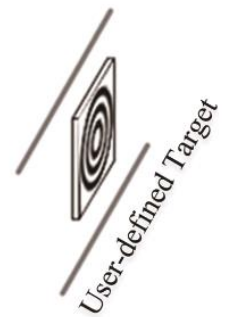

User-defined targets on the slope

Stereo images preprocessing

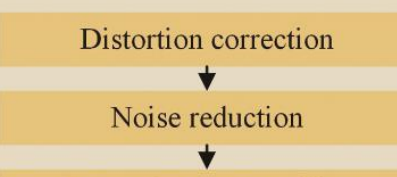

Stereo images matching

Tracking of objects

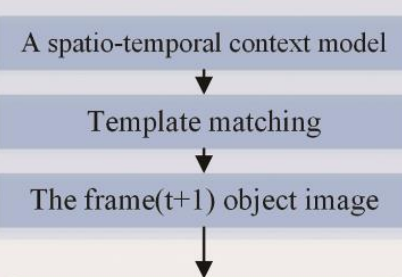

Targets centre location

\section{Extracting subpixel edges \\ Ellipse Fitting of edges \\ Clustering ellipse centres}

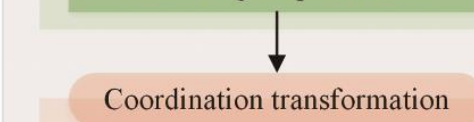

Coordination transformation

Camera calibration parameters
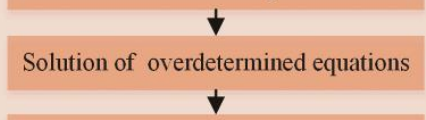

Space coordinates

Slope displacement value

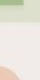

(a)

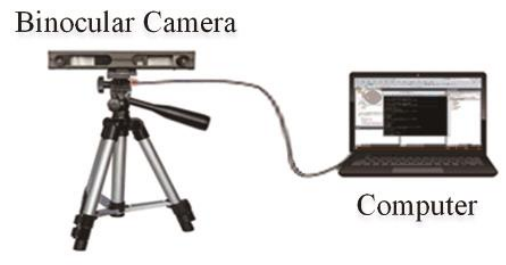

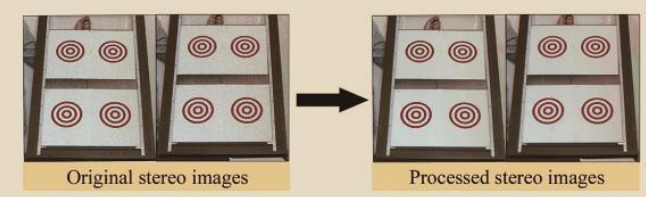

Original stereo images

Ptessed stereo images
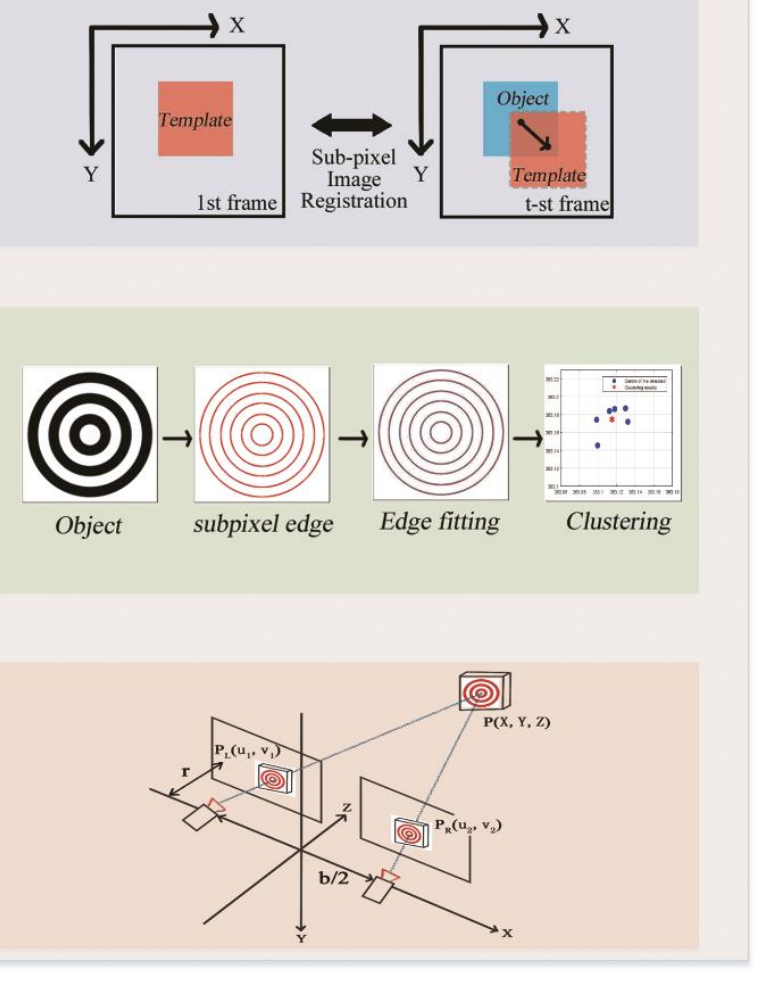

(b)

Figure 1. Displacement measurement system based on binocular vision technology: (a) hardware and (b) software. 


\subsection{Target Design}

Visual measurement technology is based on marker imaging. It must be clear that the precise positioning of an object requires searching for obvious feature points. Natural targets are often used in low-precision or near-distance measurements, whereas artificial targets are often used in high-precision or long-distance measurements, particularly for large-scale outdoor engineering structures such as slopes. In this chapter, the design and positioning methods of existing mark points are proposed to achieve the high-precision positioning of the measuring points.

\subsubsection{Design Scheme}

A round mark point is one of the most common forms of feature points in monitoring. However, a circle shows an elliptical shape after a perspective projection in computer vision imaging. In general, region- and edge-based technologies are used in elliptical centre positioning. The former is inefficient in terms of its operation, and has difficulty ensuring the noise removal effect, and thus it cannot adapt to the complex environment of a slope-engineering site. Instead, the latter can effectively avoid these problems [37]. Therefore, this study uses edge-based elliptical centre positioning technology.

Ellipse fitting technology has been widely used owing to its good fault tolerance, adaptive noise environment, and high efficiency in achieving centre positioning. The basis of the ellipse fitting technique is to obtain the edge information of an image. This study uses sub-pixel edge detection technology to achieve high-precision edge extraction, providing the best edge information for the centre positioning.

After obtaining the centre coordination of each circular mark, the clustering algorithm is used to gain the representative value of the centre of the circle, avoiding the influence of singular values and random errors on the centre orientation.

\subsubsection{Object Positioning Method}

Remote monitoring requires higher accuracy. This study uses the modified template of Gao et al. [38] to extract concentric sub-pixel edges, the basic principle of which is as follows: calculate the edge parameters according to the rotational invariance of the Zernike moment, and use the edge parameters to determine whether it is an edge to accurately extract the edge position. An ellipse is then fitted using the least squares method [39] to locate the centre coordinates of each concentric circle:

$$
\begin{aligned}
& x_{c}=\frac{b e-2 c d}{4 a c-b^{2}} \\
& y_{c}=\frac{b d-2 a e}{4 a c-b^{2}}
\end{aligned}
$$

$a, b, c, d, e$ are the coefficients of the general equation of the ellipse $a x^{2}+b x y+c y^{2}+d x+e y+f=0$, and $f$ is a constant. Finally, the value of the centre is extracted based on the k-means clustering algorithm [40]. The basic principle lies in the optimisation of the following formula:

$$
J=\sum_{n=1}^{N} \sum_{k=1}^{K} r_{n k}\left\|x_{n}-\mu_{k}\right\|^{2}
$$

In this equation, $N$ represents the number of data samples; $K$ is the number of clusters; $r_{n k}$ represents 1 when data point $n$ is assigned to class $k$, and is 0 otherwise; $x_{n}$ indicates the sample data object; and $\mu_{k}$ is the cluster centre.

The method in this study achieves the function of target centre location through programming (see Figure 2). 


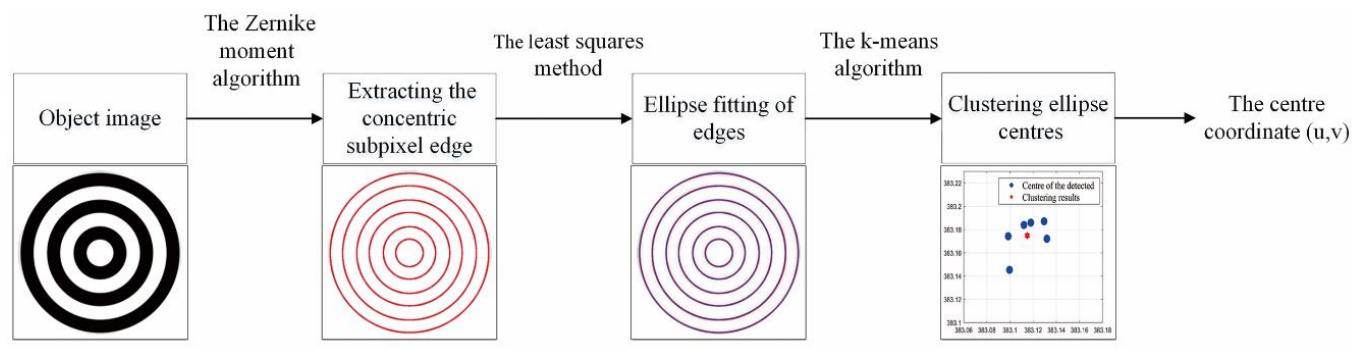

Figure 2. Target location process.

\subsubsection{Target Parameter Design}

\section{(1) Number of Circles}

The optimal number of concentric circles is determined based on the central location technology of the marked points described in the previous section. The test image is an idealised concentric circle of different layers with a size of $1712 \times 1712$ pixels, and the 2-layer concentric circles are minimal, with diameters of $10 \mathrm{~mm}$ and $20 \mathrm{~mm}$, respectively. Then, we add circles outside the previous 2-layer concentric circles with a bigger $5 \mathrm{~mm}$ radius in other six patterns of concentric circles.

As shown in Table 1 and Figure 3, errors of the target coordinates generally decrease with the increase in concentric circles and then experience a relatively stable stage at layer 6 to 10 . With the continuous increase in concentric circles, errors also rise almost linearly. Considering that in field measurement, when the number of concentric circles increases, the size of the targets increases accordingly, and the image noise caused by environmental factors such as air flow will also increase. To avoid this problem and save the early time cost, this study suggests setting the number of concentric layers to six (see Figure 3). At the same time, we can see that the algorithm has a deviation of 0.4 pixels. Since this deviation is stable, the center of each positioning is almost constant, so the accuracy requirements of the measurement system are met.

Table 1. Error analysis of different concentric circle tests.

\begin{tabular}{cccccccc}
\hline \multirow{2}{*}{$\begin{array}{c}\text { Number } \\
\text { of Circles }\end{array}$} & \multicolumn{2}{c}{ Measured Coordinates (pixel) } & \multicolumn{2}{c}{ True Coordinates (pixel) } & \multicolumn{2}{c}{ Error (pixel) } & Time \\
\cline { 2 - 8 } & $\boldsymbol{u}$ & $\boldsymbol{v}$ & $\boldsymbol{u}$ & $\boldsymbol{v}$ & $\boldsymbol{u}$ & $\boldsymbol{v}$ & $\boldsymbol{( m s )}$ \\
\hline 2 & 855.620117 & 855.671021 & 856 & 856 & 0.379883 & 0.328979 & 3707 \\
4 & 855.615845 & 855.675781 & 856 & 856 & 0.384155 & 0.324219 & 3885 \\
6 & 855.619934 & 855.677551 & 856 & 856 & 0.380066 & 0.322449 & 4134 \\
8 & 855.619080 & 855.677856 & 856 & 856 & 0.380920 & 0.322144 & 4337 \\
10 & 855.618164 & 855.677368 & 856 & 856 & 0.381836 & 0.322632 & 4477 \\
12 & 855.611511 & 855.672791 & 856 & 856 & 0.388489 & 0.327209 & 4849 \\
14 & 855.605957 & 855.669495 & 856 & 856 & 0.394043 & 0.330505 & 5184 \\
\hline
\end{tabular}

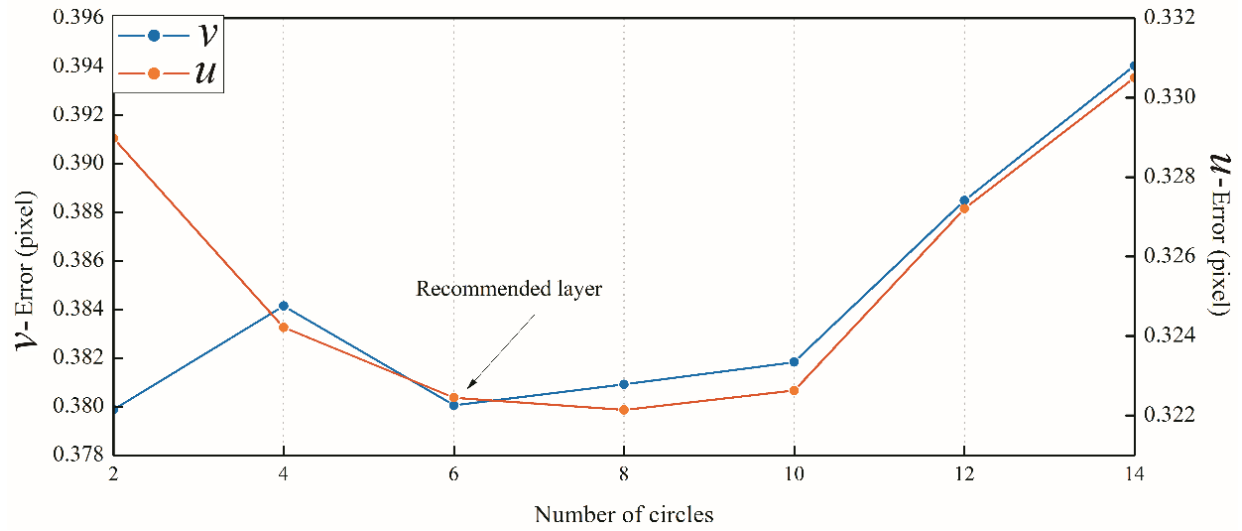

Figure 3. Analysis of test results of concentric circles. 
(2) Minimum positioning size

At different measurement distances, the pixel sizes of the targets in the image plane of the camera are inconsistent. This study will use six concentric (ellipse) circles with different pixel sizes to obtain the minimum detectable pixel size through the above-mentioned centring location technique, and thus provide guidance for a slope monitoring landmark design.

From the positioning error analysis results (see Table 2), the positioning point is located on the upper-left side of the theoretical point when the pixel resolution is above $28 \times 28$ pixels. The positioning error $u$ is between 0.34 and 0.42 , and the floating range is 0.07 pixels. Meanwhile, the positioning error $v$ is between 0.25 and 0.40 , and the floating range is 0.25 pixels. It can be seen that the center of its positioning is relatively stable. In summary, this study suggests that the concentric pixel resolution should be greater than $28 \times 28$ pixels to ensure its effective positioning.

Table 2. Concentric testing of different pixel dimensions.

\begin{tabular}{|c|c|c|c|c|c|c|c|c|}
\hline \multirow{2}{*}{$\begin{array}{c}\text { Size } \\
\text { (pixels) }\end{array}$} & \multirow{2}{*}{ Classify } & \multirow{2}{*}{$\begin{array}{l}\text { Number of } \\
\text { Circles } \\
\text { Detected }\end{array}$} & \multicolumn{2}{|c|}{$\begin{array}{l}\text { Clustering Coordinates } \\
\text { (pixels) }\end{array}$} & \multicolumn{2}{|c|}{$\begin{array}{l}\text { True Coordinates } \\
\text { (pixels) }\end{array}$} & \multicolumn{2}{|c|}{ Error (pixels) } \\
\hline & & & $u$ & $v$ & $u$ & $v$ & $u$ & $v$ \\
\hline \multirow[b]{2}{*}{$41 \times 41$} & circle & 6 & 20.154753 & 20.214046 & 20.5 & 20.5 & 0.345247 & 0.285954 \\
\hline & ellipse & 6 & 20.08853 & 20.192606 & 20.5 & 20.5 & 0.41147 & 0.307394 \\
\hline \multirow{2}{*}{$36 \times 36$} & circle & 6 & 17.625174 & 17.636324 & 18 & 18 & 0.374826 & 0.363676 \\
\hline & ellipse & 6 & 17.594893 & 17.673111 & 18 & 18 & 0.405107 & 0.326889 \\
\hline \multirow{2}{*}{$30 \times 30$} & circle & 6 & 14.616336 & 14.700969 & 15 & 15 & 0.383664 & 0.299031 \\
\hline & ellipse & 6 & 14.589076 & 14.743123 & 15 & 15 & 0.410924 & 0.256877 \\
\hline \multirow{2}{*}{$28 \times 28$} & circle & 6 & 13.625415 & 13.72232 & 14 & 14 & 0.374585 & 0.27768 \\
\hline & ellipse & 6 & 13.612086 & 13.60793 & 14 & 14 & 0.387914 & 0.39207 \\
\hline \multirow{2}{*}{$25 \times 25$} & circle & 5 & 13.420197 & 11.999551 & 12.5 & 12.5 & -0.9202 & 0.500449 \\
\hline & ellipse & 6 & 12.436928 & 13.601745 & 12.5 & 12.5 & 0.063072 & -1.10175 \\
\hline
\end{tabular}

\subsubsection{Noise Robustness}

In image processing, noise is a ubiquitous phenomenon with great interference. In engineering applications, the obtained image is different from the "real" image due to the factors such as image acquisition equipment and natural environment. This part of difference is noise. In this section, the simulation noise image is used to verify the stability of the algorithm. At present, the image noise is mainly gaussian noise and salt noise.

In this study, the 6-layer concentric circle images, a size of $767 \times 767$ pixels, with different variance Gaussian noise and different density impulse noise were obtained by means of Matlab simulation, and then the positioning experiment was carried out. Compared with the measured values in the non-noise case, the error of the proposed algorithm under the influence of noise is calculated. Finally, the stability of the proposed algorithm in dealing with noise is verified by comparison with the gravity method [23] based on regional positioning.

As shown in Figure 4, when we increase the two noise levels to 0.08 respectively, we can see from the error analysis results that the fluctuation of the gravity method represented by the blue curve is significantly higher than that of the red curve. Locally, the centering technique based on the gravity method has a mis-positioning point when the impulse noise density reaches 0.05 , and the center positioning cannot be achieved. The algorithm proposed in this study can still achieve accurate positioning when the impulse noise density reaches 0.08 , and the maximum error is only 0.0183 (see Table 3). It is proved that the concentric center positioning method proposed in this study shows better accuracy and stability when dealing with noise. 


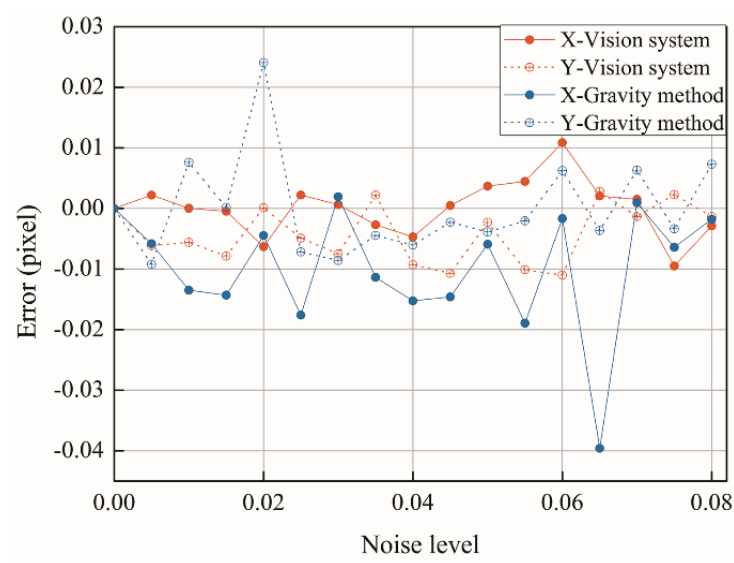

(a)

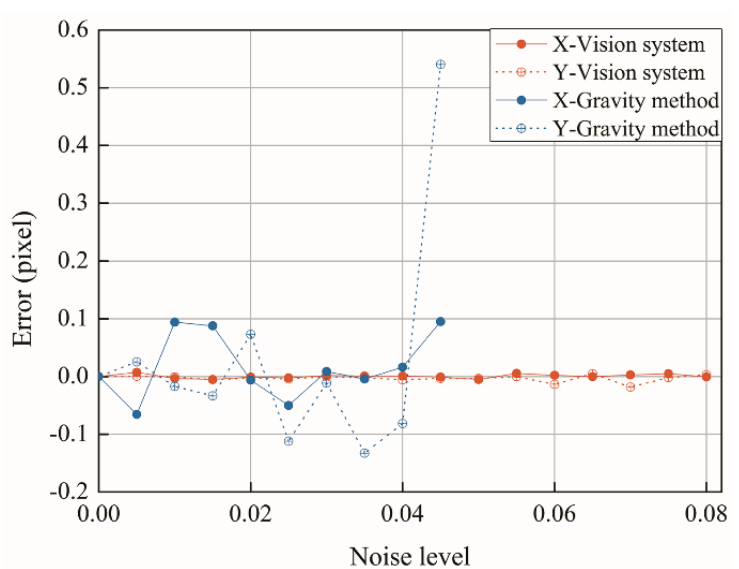

(b)

Figure 4. Positioning error of marker points under the influence of noise; (a) Considering Gaussian noise; (b) Considering impulse noise.

Table 3. Positioning error of marker points under the influence of noise.

\begin{tabular}{|c|c|c|c|c|c|c|c|c|c|}
\hline \multirow{3}{*}{ Number } & \multirow{3}{*}{$\begin{array}{l}\text { Noise } \\
\text { Level }\end{array}$} & \multicolumn{4}{|c|}{ Gaussian Noise Error (pixels) } & \multicolumn{4}{|c|}{ Impulse Noise Error (pixels) } \\
\hline & & \multicolumn{2}{|c|}{ Vision System } & \multicolumn{2}{|c|}{ Gravity Method } & \multicolumn{2}{|c|}{ Vision System } & \multicolumn{2}{|c|}{ Gravity Method } \\
\hline & & $u$ & $v$ & $u$ & $v$ & $u$ & $v$ & $u$ & $v$ \\
\hline 1 & 0 & 0 & 0 & 0 & 0 & 0 & 0 & 0 & 0 \\
\hline 2 & 0.005 & 0.002198 & -0.00613 & -0.00582 & -0.00922 & 0.007202 & 0.000458 & -0.06564 & 0.025549 \\
\hline 3 & 0.01 & 0.000031 & -0.00558 & -0.01349 & 0.007616 & -0.00336 & -0.00061 & 0.094164 & -0.01722 \\
\hline 4 & 0.015 & -0.000457 & -0.00784 & -0.0143 & 0.000161 & -0.00513 & -0.00552 & 0.087803 & -0.0336 \\
\hline 5 & 0.02 & -0.006286 & 0.000122 & -0.00445 & 0.024084 & -0.00107 & -0.00293 & -0.00639 & 0.072873 \\
\hline 6 & 0.025 & 0.002228 & -0.00488 & -0.01759 & -0.00717 & -0.00241 & -0.00424 & -0.05005 & -0.11229 \\
\hline 7 & 0.03 & 0.000641 & -0.00748 & 0.001939 & -0.00858 & 0.001587 & -0.00052 & 0.008688 & -0.01136 \\
\hline 8 & 0.035 & -0.002685 & 0.002228 & -0.01136 & -0.00445 & 0.000977 & -0.00198 & -0.00427 & -0.13275 \\
\hline 9 & 0.04 & -0.004699 & -0.00928 & -0.01524 & -0.00603 & 0.000977 & -0.00598 & 0.016176 & -0.08148 \\
\hline 10 & 0.045 & 0.000489 & -0.01071 & -0.01459 & -0.00226 & -0.00095 & -0.00345 & 0.09499 & 0.540542 \\
\hline 11 & 0.05 & 0.003693 & -0.00229 & -0.0059 & -0.00388 & -0.00513 & -0.00339 & - & - \\
\hline 12 & 0.055 & 0.004456 & -0.0101 & -0.01893 & -0.00204 & 0.005402 & -0.00037 & - & - \\
\hline 13 & 0.06 & 0.010865 & -0.01099 & -0.00166 & 0.006228 & 0.001984 & -0.01364 & - & - \\
\hline 14 & 0.065 & 0.002076 & 0.002808 & -0.03957 & -0.00365 & -0.00018 & 0.004792 & - & - \\
\hline 15 & 0.07 & 0.001526 & -0.00134 & 0.000937 & 0.006315 & 0.002747 & -0.01834 & - & - \\
\hline 16 & 0.075 & -0.009491 & 0.002289 & -0.0064 & -0.00334 & 0.004792 & -0.00192 & - & - \\
\hline 17 & 0.08 & -0.002868 & -0.00134 & -0.00178 & 0.007308 & -0.00082 & 0.002961 & - & - \\
\hline
\end{tabular}

\subsection{Target Tracking}

\subsubsection{Theory}

The STC tracking algorithm and sub-pixel image registration technology are employed to improve the target tracking accuracy. Theoretically, the accuracy of this method can probably increase to the sub-pixel level while maintaining the high speed of the STC algorithm. The basic flow is shown in Figure 5.

Step 1: Target pixel-level positioning based on a confidence map. In the first frame, we suppose that the target location has been manually initialised. At the $t$-th frame, we learn the spatial context model $h^{s c}(x)$ for (3) updating the spatio-temporal context model $H_{t+1}^{s t c}(4)$ and apply it to detect the object location in the $(t+1)$-th frame. The object location $x_{t+1}^{*}(5)$ in the $(t+1)$-th frame is determined by maximising the new confidence map.

$$
h^{s c}(x)=F^{-1}\left(\frac{F\left(b e^{-\left|\frac{x-x^{*}}{\alpha}\right|^{\beta}}\right)}{F\left(I(x) \omega_{\sigma}\left(x-x^{*}\right)\right)}\right)
$$




$$
\begin{gathered}
H_{t+1}^{s t c}=(1-\rho) H_{t}^{s t c}+\rho h_{t}^{s c} \\
x_{t+1}^{*}=\underset{x \in \Omega_{c}\left(x_{t}^{*}\right)}{\operatorname{argmax} c_{t+1}}(x)
\end{gathered}
$$

where $c_{t+1}(x)$ is represented as

$$
c_{t+1}(x)=F^{-1}\left(F\left(H_{t+1}^{s t c}(x)\right) \bigotimes F\left(I_{t+1}(x) \omega_{\sigma t}\left(x-x_{t}^{*}\right)\right)\right)
$$

In this function, $F$ denotes the fast Fourier transform function, $F^{-1}$ is the inverse of $F, b$ is a normalisation constant, $\alpha$ is a scale parameter, $\beta$ is a shape parameter, $I()$ is the image intensity that represents the appearance of the context, and $\omega_{\sigma}()$ is the weighted function defined by

$$
\omega_{\sigma}(z)=a e^{-\frac{|z|^{2}}{\sigma^{2}}}
$$

where $a$ is a normalisation constant, and $\sigma$ is a scale parameter.

Step 2: Target sub-pixel-level location based on image registration. UCC template matching technology is used to conduct template matching between the target and template images. The cross-correlation in the neighbourhood of $1.5 \times 1.5$ pixels with respect to the initial estimate is calculated using the up-sampling factor $\mathrm{k}$, which can achieve a $1 / \mathrm{k}$ registration accuracy of the pixel, eliminate the tracking drift, and allow the tracking process to reach the sub-pixel accuracy. The specific process is as follows:

We assume that the $\mathrm{t}$-frame target tracking image is $f(x, y)$, template image is $g(x, y)$, and the amount of drift between the two images is $(d x, d y)$.

$$
g(x, y)=f(x-d x, y-d y)
$$

Convert the image into frequency domain using Fourier transforms:

$$
G(u, v)=F(u, v) * e^{-i * 2 \pi *(u d x+v d y)}
$$

Divide the above equation to obtain the cross power spectrum:

$$
H(u, v)=\frac{G(u, v) F^{*}(u, v)}{|G(u, v)| *\left|F^{*}(u, v)\right|}=e^{-i * 2 \pi *(u d x+v d y)}
$$

In this function, $F^{*}$ represents the complex conjugate of $F$. For the mutual power spectrum, the Dirac function can be obtained by inverse Fourier transform. The pixel-level registration is finally achieved by locating the peak coordinates of the Dirac function.

After achieving pixel-level registration, the pixel-level drift value of the image can be obtained, and then the sub-pixel drift coordinate extraction is implemented by using the upsampling algorithm within one pixel drift. The upsampling multiple $\mathrm{k}=100$, therefore, the registration accuracy can reach 0.01. After the image is amplified by upsampling, the image phase correlation algorithm is used to obtain the drift value of the image. Since the image drift value at this time is the result after the upsampling, it is necessary to perform the reduction in combination with the upsampling multiple, that is, multiply by 0.01 to obtain the sub-pixel drift coordinates. After obtaining the pixel-level and sub-pixel translation coordinates respectively, the final result of sub-pixel image registration can be obtained by combining the two.

In this study, the above-mentioned upsampling and image phase correlation algorithm is used to correct the drift phenomenon of the target tracking process, and then the tracking coordinates can be combined to achieve accurate target positioning. Eventually the target tracking accuracy is raised to the sub-pixel level. 


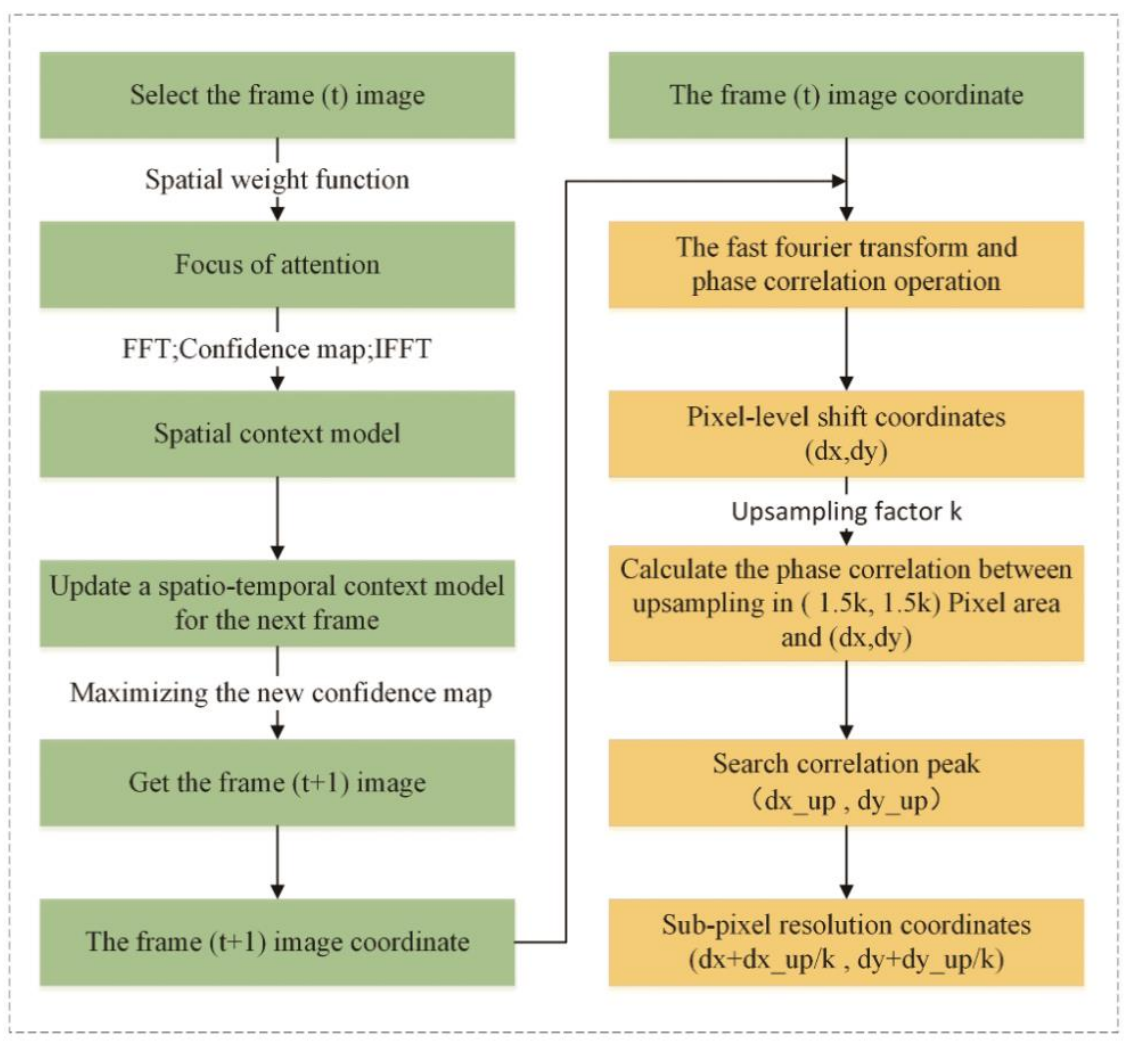

Figure 5. Flowchart of object tracking based on spatial-temporal contextual (STC) and Unsampled Cross Correlation (UCC).

\subsubsection{Performance Evaluation}

The moving platform test experiments were used to evaluate the performance of the improved STC algorithm. In this study, the MTS test machine was used to clamp the moving plate to reciprocate up and down, and it was continuously monitored by the camera. In order to better demonstrate the advantages of the improved STC algorithm, two different loading methods were set up in this study, namely linear loading and sinusoidal loading. The frequency of the MTS tester was set to $0.1 \mathrm{~Hz}$ and the amplitude was set to $9 \mathrm{~mm}$. The moving platform test setup is shown in Figure 6.

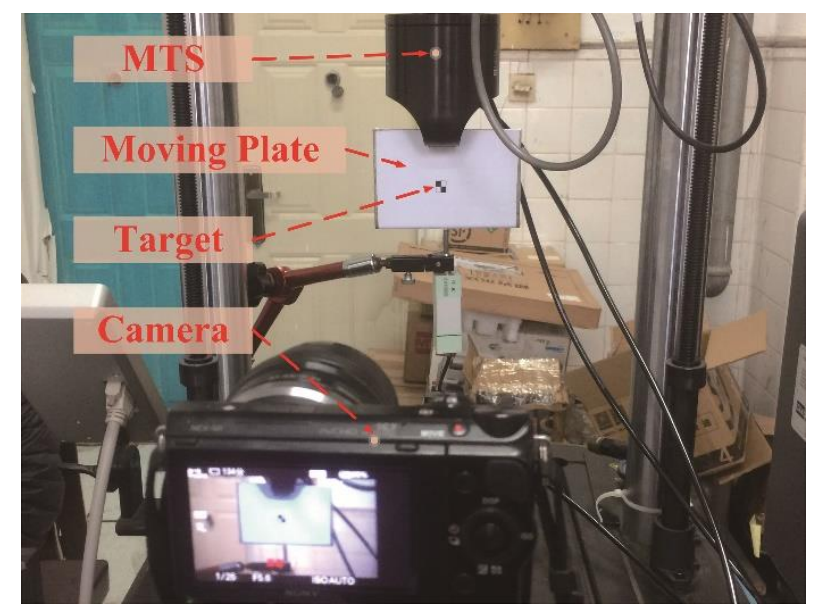

Figure 6. Setup for moving platform tests. 
After obtaining the moving plate test sequence image, the target object is tracked and detected by using the STC algorithm and the improved STC algorithm. The pixel coordinate transformation is converted into physical coordinate transformation by the scale factor calculation method [41], and the result is shown in Figure 7.

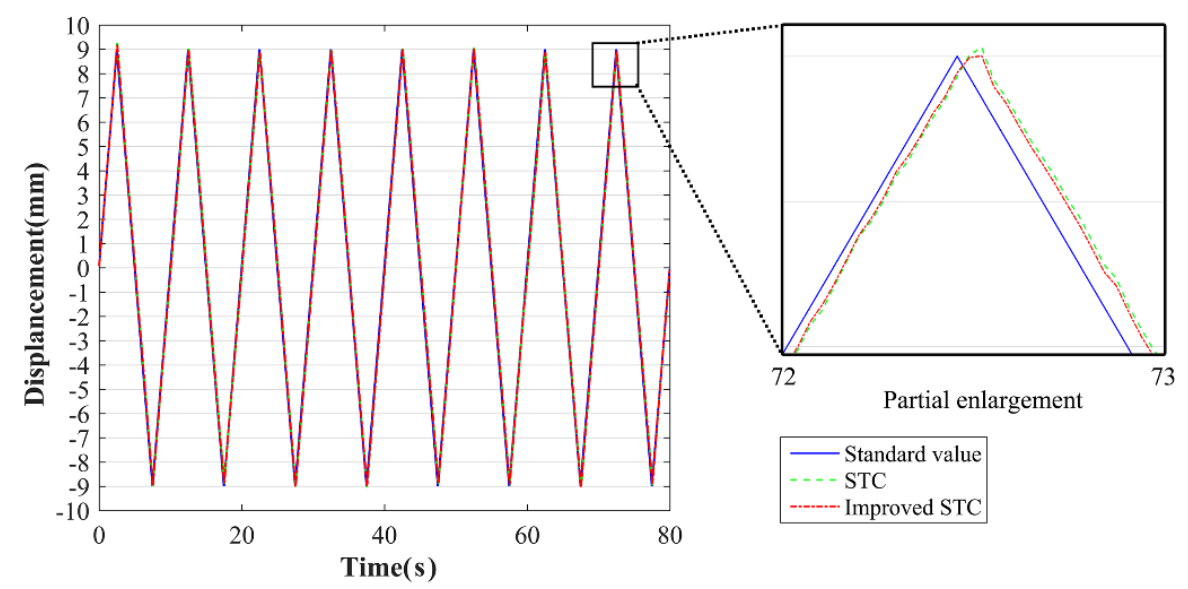

(a)

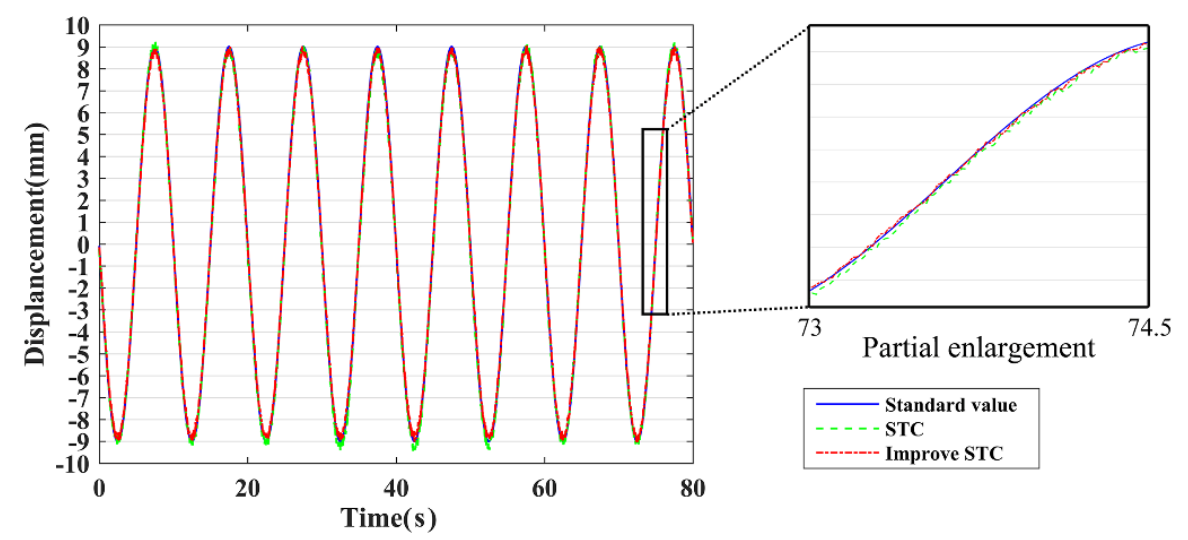

(b)

Figure 7. The moving platform tests results: (a) linear loading; (b) sinusoidal loading.

As shown in Figure 7, both the STC algorithm and the improved STC algorithm can achieve target tracking measurements. From the partial enlargement, the measured value of the improved STC algorithm is less fluctuating. According to the measurement error analysis, the normalized root mean squared error (NRMSE) of the STC algorithm is 0.0127 for linear loading, and the improved STC algorithm is 0.0106. When sinusoidal loading, NRMSE of the STC algorithm measurement is 0.0122 , and the improved STC algorithm is 0.0098 . It can be seen that the improved STC algorithm can effectively reduce the measurement error, improve the measurement accuracy, and make the measurement result more stable and reliable.

\subsection{Coordinate Transformation}

According to Zhang's calibration method [42], two coefficient matrices can be constructed by calibrating a binocular camera. The left- and right-image pixel coordinates are then combined using a coefficient matrix to solve the over-determined equations and obtain the spatial coordinates. After obtaining the spatial coordinates of the target in each frame of the image, the displacement 
value of the measurement point can be quantified to obtain the surface deformation of the slope. The calculation principle is shown in Figure 8.

$$
\begin{aligned}
& {\left[\begin{array}{c}
u_{1} \\
v_{1} \\
1
\end{array}\right]=\left[\begin{array}{llll}
p_{00}^{1} & p_{01}^{1} & p_{02}^{1} & p_{03}^{1} \\
p_{10}^{1} & p_{11}^{1} & p_{12}^{1} & p_{13}^{1} \\
p_{20}^{1} & p_{21}^{1} & p_{22}^{1} & p_{23}^{1}
\end{array}\right]\left[\begin{array}{c}
X \\
Y \\
Z \\
1
\end{array}\right]} \\
& {\left[\begin{array}{c}
u_{2} \\
v_{2} \\
1
\end{array}\right]=\left[\begin{array}{llll}
p_{00}^{2} & p_{01}^{2} & p_{02}^{2} & p_{03}^{2} \\
p_{10}^{2} & p_{11}^{2} & p_{12}^{2} & p_{13}^{2} \\
p_{20}^{2} & p_{21}^{2} & p_{22}^{2} & p_{23}^{2}
\end{array}\right]\left[\begin{array}{c}
X \\
Y \\
Z \\
1
\end{array}\right]}
\end{aligned}
$$

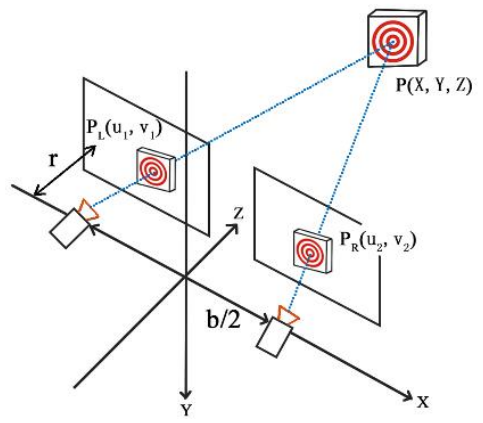

Figure 8. Schematic of binocular vision measurement.

\section{In-Laboratory Validation Test}

This chapter describes tests to verify the method proposed in this study.

\subsection{Static Distance Measurement Test}

To quantify the effect of the mark point size and centre distance on the measurement accuracy, two sets of tests are described in this section. The major instrumentation includes the targets, binocular cameras, and computer (see Figure 9). The stereo baseline is set to $12 \mathrm{~cm}$, and the distance from the camera to the measuring point is $4 \mathrm{~m}$. Then, we get the best image by manually adjusting the focus and keep it constant.
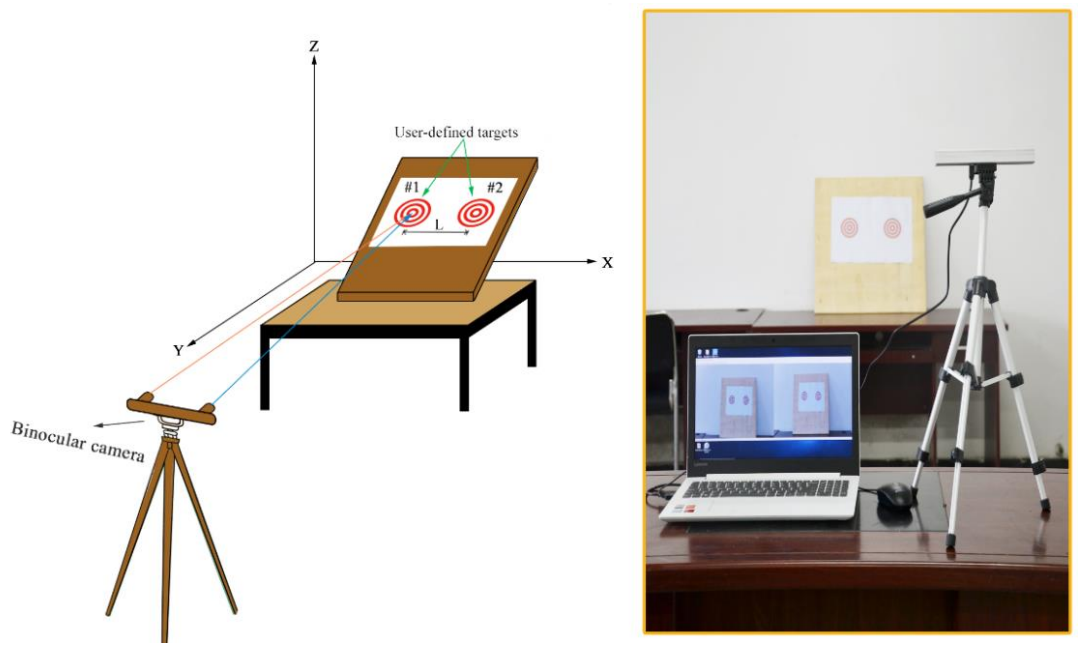

Figure 9. Setup for static distance measurement test, left: image of 3D simulation test, right: laboratory test scene. 
Test 1: The sizes of the marked points are different, and the centres of the circles are the same. The marker points were designed using eight different sizes according to the relevant parameters in Chapter 3. It is assumed that the minimum concentric diameter is $D$, the remaining diameters are $D_{n}=D \times n, n$ is an integer from 1 to 6 , and the distance between two centres is $150 \mathrm{~mm}$ accordingly, which is measured in vector drawing tool Coreldraw.

Test 2: The marked points have the same size, but the centres of the two circles are different. We chose a minimum diameter of the marker point of $15 \mathrm{~mm}$, and a distance to the circle centre of 100 to $300 \mathrm{~mm}$.

The results obtained after calculating the spatial coordinates using the proposed method in Chapter 2 are shown in Tables 4 and 5.

Table 4. Measurement results of Test 1.

\begin{tabular}{|c|c|c|c|c|c|c|c|}
\hline \multirow{2}{*}{ Number } & \multirow{2}{*}{$\begin{array}{l}\text { Minimum } \\
\text { Diameter }\end{array}$} & \multirow{2}{*}{ Pixel Size } & \multicolumn{3}{|c|}{ Target Space Coordinates } & \multirow{2}{*}{$\begin{array}{l}\text { Measurement } \\
(\mathrm{mm})\end{array}$} & \multirow{2}{*}{$\begin{array}{l}\text { Error } \\
(\mathrm{mm})\end{array}$} \\
\hline & & & $x$ & $y$ & $z$ & & \\
\hline \multirow{2}{*}{$\mathrm{I}-1$} & \multirow{2}{*}{5} & \multirow{2}{*}{$66 \times 66$} & -47.2496 & 60.7972 & 1540.49 & \multirow{2}{*}{149.7765} & \multirow{2}{*}{0.2235} \\
\hline & & & 101.466 & 64.0262 & 1522.99 & & \\
\hline \multirow{2}{*}{$\mathrm{I}-2$} & \multirow{2}{*}{7.5} & \multirow{2}{*}{$99 \times 99$} & -45.7566 & 48.5814 & 1526.84 & \multirow{2}{*}{149.8464} & \multirow{2}{*}{0.1536} \\
\hline & & & 102.9 & 55.1874 & 1544.49 & & \\
\hline \multirow{2}{*}{$\mathrm{I}-3$} & \multirow[b]{2}{*}{10} & \multirow{2}{*}{$132 \times 132$} & -72.0315 & 72.8357 & 1535.54 & \multirow[b]{2}{*}{150.2367} & \multirow{2}{*}{0.2367} \\
\hline & & & 76.8983 & 78.3795 & 1554.52 & & \\
\hline \multirow{2}{*}{$\mathrm{I}-4$} & \multirow{2}{*}{12.5} & \multirow{2}{*}{$165 \times 165$} & -45.524 & 70.3383 & 1534.15 & \multirow{2}{*}{149.7905} & \multirow{2}{*}{0.2095} \\
\hline & & & 101.925 & 71.9863 & 1507.82 & & \\
\hline \multirow{2}{*}{$\mathrm{I}-5$} & \multirow[b]{2}{*}{15} & \multirow{2}{*}{$198 \times 198$} & -33.9774 & 64.1482 & 1523.63 & \multirow{2}{*}{149.8362} & \multirow{2}{*}{0.1638} \\
\hline & & & 115.1 & 67.5548 & 1538.3 & & \\
\hline \multirow{2}{*}{ I-6 } & \multirow{2}{*}{17.5} & \multirow{2}{*}{$231 \times 231$} & -84.4728 & 90.9581 & 1536.39 & \multirow{2}{*}{149.7684} & \multirow{2}{*}{0.2316} \\
\hline & & & 63.3845 & 91.6196 & 1512.55 & & \\
\hline & & & -37.0946 & 87.539 & 1517.28 & & 01254 \\
\hline $1-7$ & 20 & & 108.986 & 84.4612 & 1482.76 & 150.1354 & 0.1354 \\
\hline 8 & 5 & & -101.026 & 85.8391 & 1518.59 & & \\
\hline $1-8$ & 22.5 & 297 & 46.4737 & 86.6175 & 1492.36 & 149.8158 & 0.1842 \\
\hline
\end{tabular}

Table 5. Measurement results of Test 2.

\begin{tabular}{|c|c|c|c|c|c|c|}
\hline \multirow{2}{*}{ Number } & \multirow{2}{*}{ Real (mm) } & \multicolumn{3}{|c|}{ Target Space Coordinates } & \multirow{2}{*}{$\begin{array}{l}\text { Measurement } \\
\quad(\mathrm{mm})\end{array}$} & \multirow{2}{*}{ Error $(\mathrm{mm})$} \\
\hline & & $x$ & $y$ & $z$ & & \\
\hline \multirow{2}{*}{ II-1 } & \multirow{2}{*}{100} & -31.187 & 95.2045 & 1529.29 & \multirow{2}{*}{100.1681} & \multirow{2}{*}{0.1681} \\
\hline & & 66.6902 & 95.3143 & 1507.99 & & \\
\hline \multirow{2}{*}{ II-2 } & \multirow{2}{*}{125} & 15.1994 & 81.9168 & 1526.35 & \multirow{2}{*}{124.7468} & \multirow{2}{*}{0.2532} \\
\hline & & 139.581 & 85.3977 & 1535.23 & & \\
\hline \multirow{2}{*}{ II-3 } & \multirow{2}{*}{150} & -33.9774 & 64.1482 & 1523.63 & \multirow{2}{*}{149.8362} & \multirow{2}{*}{0.1638} \\
\hline & & 115.1 & 67.5548 & 1538.3 & & \\
\hline \multirow{2}{*}{ II-4 } & \multirow{2}{*}{175} & -84.989 & 109.588 & 1543.95 & \multirow{2}{*}{174.8049} & \multirow{2}{*}{0.1951} \\
\hline & & 87.5032 & 109.406 & 1515.61 & & \\
\hline \multirow{2}{*}{ II-5 } & \multirow{2}{*}{200} & -36.0215 & 65.7006 & 1538.77 & \multirow{2}{*}{200.1552} & \multirow{2}{*}{0.1552} \\
\hline & & 163.315 & 67.5481 & 1556.76 & & \\
\hline \multirow{2}{*}{ II-6 } & \multirow{2}{*}{225} & -86.3799 & 60.4379 & 1544.6 & \multirow{2}{*}{225.26} & \multirow{2}{*}{0.26} \\
\hline & & 137 & 61.2969 & 1573.63 & & \\
\hline \multirow{2}{*}{ II-7 } & \multirow{2}{*}{250} & -65.7222 & 107.195 & 1540.87 & \multirow{2}{*}{250.1702} & \multirow{2}{*}{0.1702} \\
\hline & & 183.541 & 113.807 & 1561.1 & & \\
\hline \multirow{2}{*}{ II-8 } & \multirow[b]{2}{*}{275} & -52.424 & 74.3521 & 1516.97 & \multirow{2}{*}{275.2898} & \\
\hline & & 221.944 & 80.5141 & 1538.62 & & 0.2898 \\
\hline II_0 & & -144.008 & 67.8541 & 1520.25 & & \\
\hline $11-9$ & 300 & 154.401 & 74.3054 & 1553.11 & 300.2821 & 0.2821 \\
\hline
\end{tabular}


As can be seen from the above table, during the testing of different target size measurements, the distance between the two markers was measured using a stereo-vision system. The mean value of the measurement error is $0.1923 \mathrm{~mm}$, and the maximum error is $0.2367 \mathrm{~mm}$. During the testing of the circle centre distance for different sign points, the average value of the measurement error is 0.2153 $\mathrm{mm}$, and the maximum error is $0.2898 \mathrm{~mm}$. This shows that the system can achieve millimetre level accuracy in monitoring, and ensure the accuracy of the spatial coordinate measurements. Furthermore, the development of its error has no obvious relationship with the marked point size and the distance from the centre of the circle, and thus can reach the millimetre level in any sized measurement of the mark.

\subsection{Moving Platform Experiment}

The above distance measurement test verifies the accuracy of the system proposed in this paper. However, the test capture process is static and cannot be used to verify the feasibility of the system. Based on this research, the laboratory model test is used to verify the tracking and positioning accuracy of the system. The overall layout of the test is shown in Figure 10. The test instruments included slidable panels, binocular cameras, Vernier callipers, and laptops. The slidable squad consists of two plates that can slide up and down, and can simulate the local deformation and overall deformation, respectively. To compare and analyse the accuracy, the sliding distance is obtained using the binocular stereo-vision system and Vernier calliper, respectively.
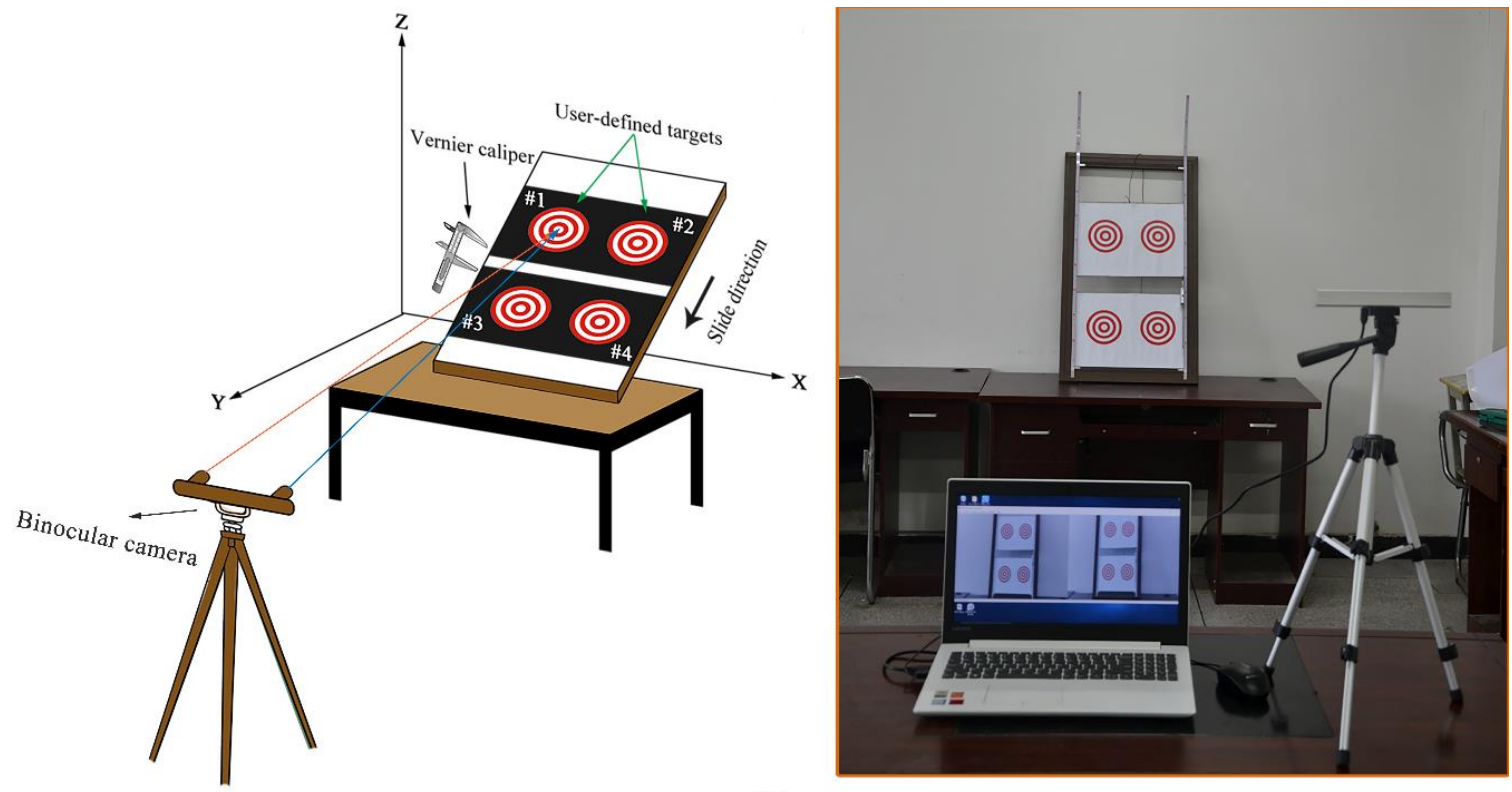

(a)

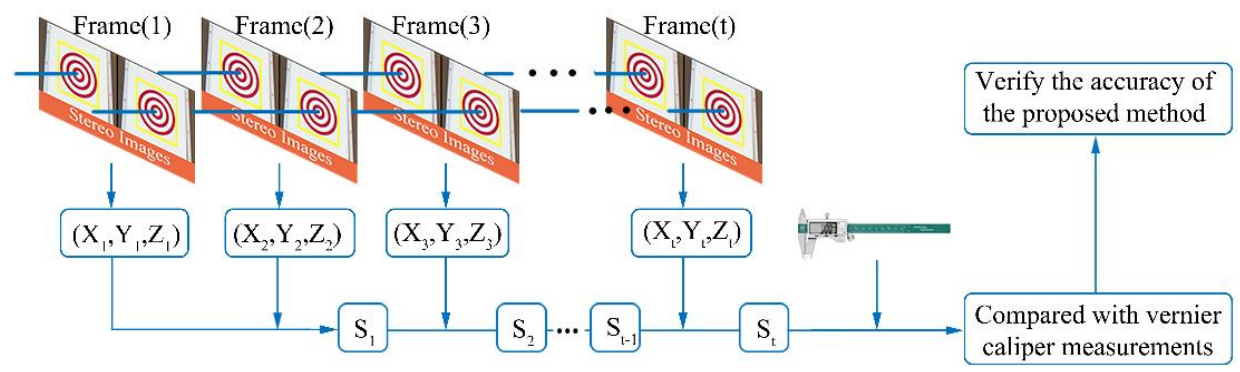

(b)

Figure 10. Moving platform experiment: (a) test site settings and (b) experimental procedure. 
Test 1: Local deformation monitoring test. The lower plate is fixed in the sliding plate group, and the upper plate is moved slowly downwards. At the same time, a Vernier calliper and a binocular stereo-vision system are used to measure the distance between the two objects in the upper plate. A total of 34 frames are tested.

Test 2: Overall deformation monitoring test. The slope deformation is simulated by connecting the upper and lower plates, and moving them slowly at the same time. The displacement is quantified by monitoring the changes in the spatial position of the four landmarks.

The test results obtained are shown in Figures 11-13.

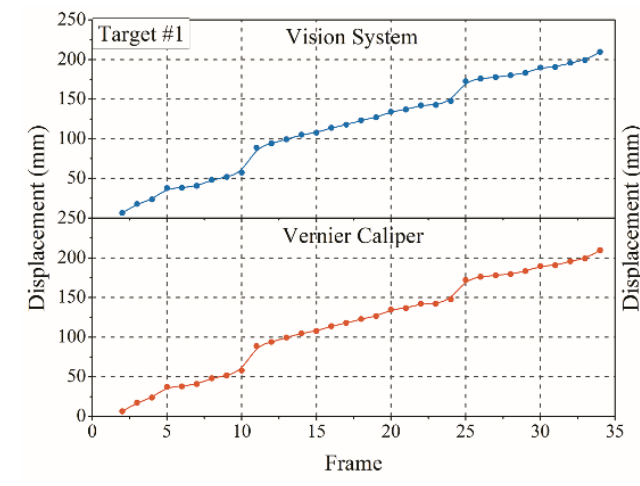

(a)

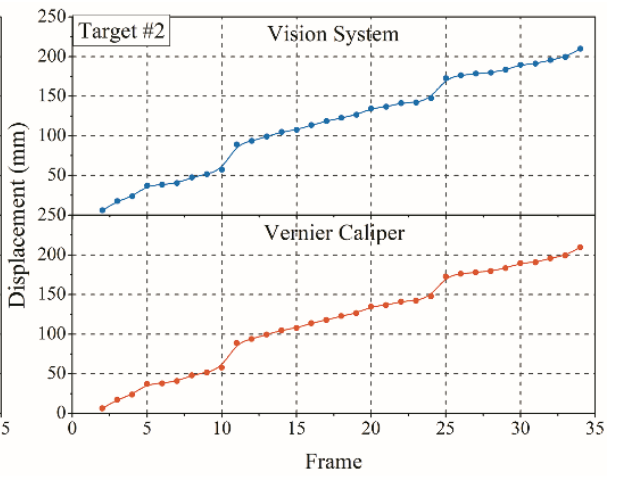

(b)

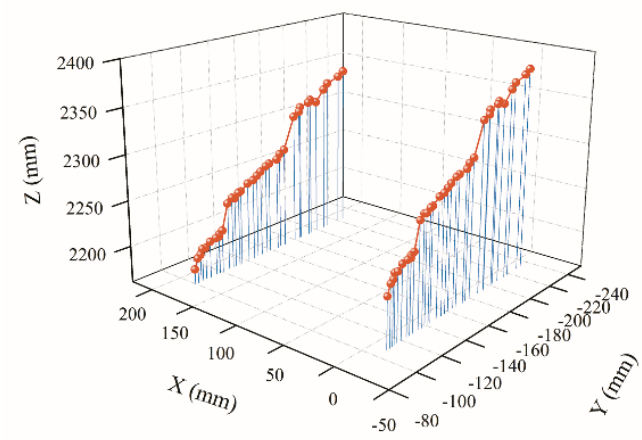

(c)

Figure 11. Local deformation marker point displacement monitoring results: (a) target 1, (b) target 2 , and (c) spatial results.

It can be seen from the above test data that the spatial displacement value tracked by the binocular stereo-vision measurement system is compared with the displacement value measured using the Vernier calliper. Through local deformation monitoring error can be obtained (see Figures 11 and 13a), The average value of the error is $0.2568 \mathrm{~mm}$, and the maximum error is $0.5427 \mathrm{~mm}$. Only five of the 68 groups of measurement data have errors exceeding $0.5 \mathrm{~mm}$, which proves that the binocular stereo-vision measurement system has strong tracking and positioning stability. The results of the overall deformation-monitoring test are shown in Figures 12 and $13 \mathrm{~b}$. The average values of the monitoring errors for each marker are $0.2503,0.2995,0.2404$, and $0.2619 \mathrm{~mm}$, respectively, and the maximum error is $0.9219 \mathrm{~mm}$. In the two hundred groups of stereo-vision system measurements, there are three groups with errors exceeding $0.8 \mathrm{~mm}$, six groups with errors exceeding $0.7 \mathrm{~mm}$, and eight groups with errors exceeding $0.6 \mathrm{~mm}$. In addition, the mean and maximum values of the error are increased relative to the static measurement test. This is because there is a certain error in the target-tracking process, which causes the average error and fluctuation range to increase. 

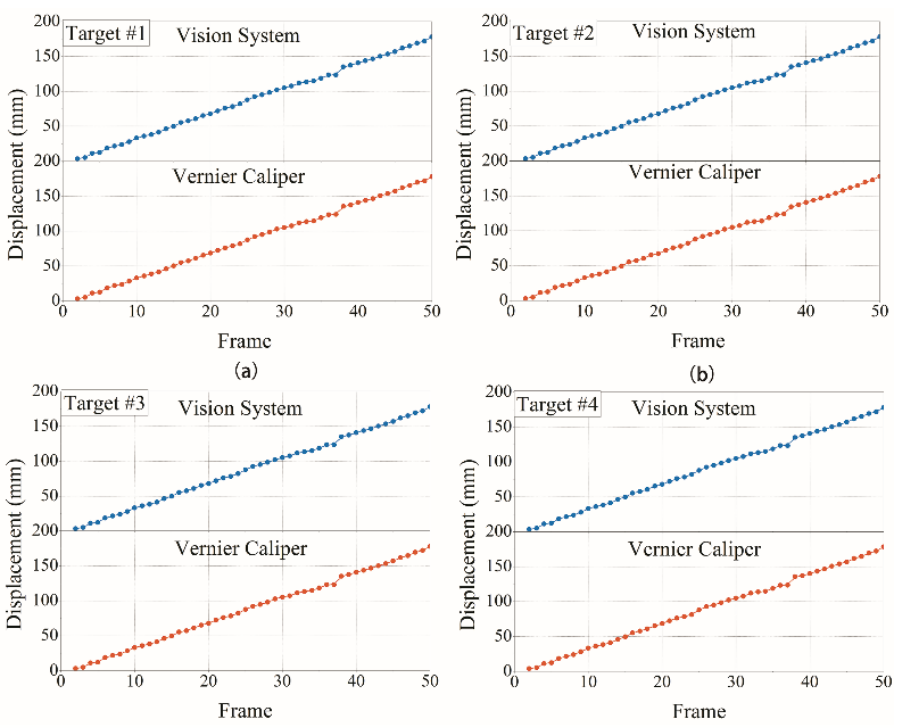

(b)

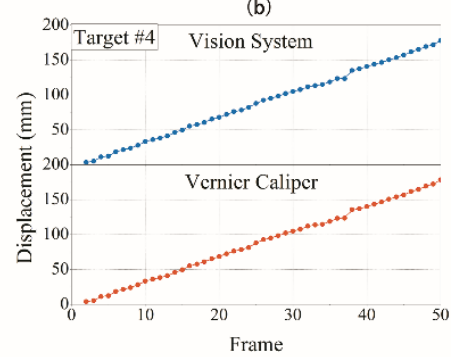

(c)

(d)

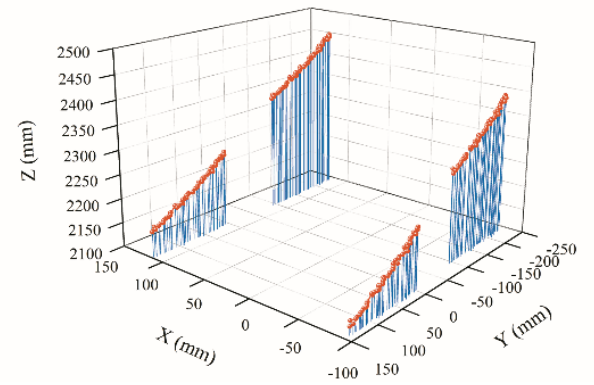

(e)

Figure 12. Overall deformation marker point displacement monitoring results: (a) target 1, (b) target 2, (c) target 3, (d) target 4 , and (e) spatial results.

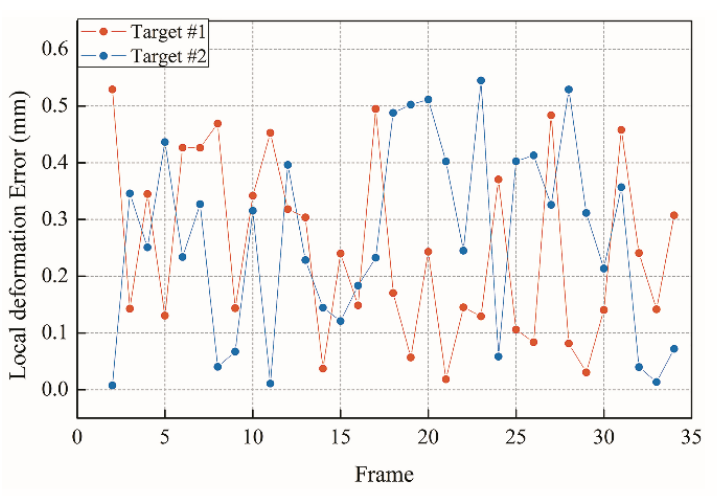

(a)

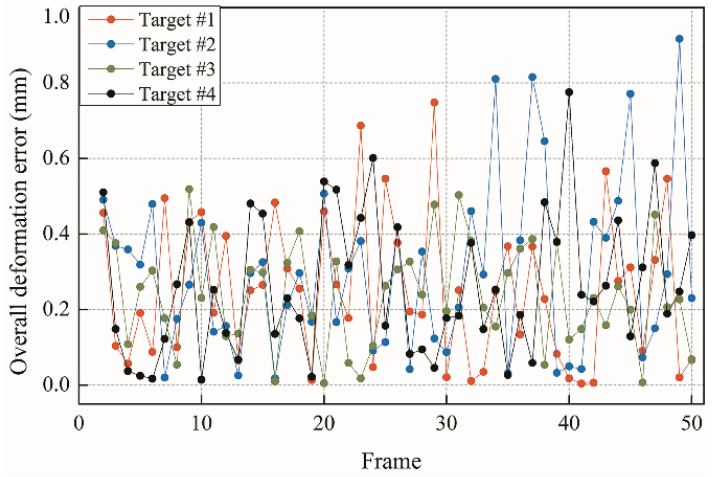

(b)

Figure 13. Results of measurement error: (a) Local deformation; (b) Overall deformation.

\section{Conclusions}

The exploration of structural health monitoring based on vision sensors is still in its infancy. In this study, a non-contact dynamic displacement measurement system with binocular stereo vision is designed. The slope is used as a carrier to explore the possibility of tracking and positioning technology to monitor the three-dimensional deformation of the structure. The specific conclusions are as follows:

(1) Target markers adapted to the monitoring system are specially designed as concentric circles. Considering the error of program operation, graphics positioning size and time cost, the research 
suggests setting the number of concentric layers to six, and the pixel size of the marker points to no smaller than $28 \times 28$ pixels. Under the design of the target, it can be seen from the noise robustness test that the positioning method has better positioning accuracy and stability under different levels of Gaussian noise and impulse noise than the center of gravity method.

(2) This study successfully introduces the target tracking technology into the deformation monitoring of the slope and improves the degree of intelligence. The tracking performance evaluation test shows that the use of UCC sub-pixel template matching technology to optimize the tracking accuracy of an STC target can effectively reduce the measurement error.

(3) Finally, slope movement is simulated by the indoor sliding plate, and the deformation is monitored employing the proposed method. The results show that the accuracy of the deformation measurement can achieve a millimeter level. It validates the potentials of the stereo vision displacement sensor for cost-effective slope health monitoring. However, the actual slope application needs to be further explored according to the actual situation.

The vision sensor system proposed in this paper can also be applied to deformation monitoring scenarios in other engineering fields, such as bridge deflection, tunnel convergence, and also structural deformation. However, detailed monitoring plans in these circumstances should take into full consideration specific site conditions and the primary monitoring objects closely related to the structural health.

Author Contributions: The asterisk indicates the corresponding author, and the first two authors contributed equally to this work. The vision sensor system is developed by J.T. and S.H., under the supervision of Q.H. and L.H. Experiment planning, setup and measurement of laboratory tests are conducted by Q.C., Y.F., S.T. provided valuable insight in preparing this manuscript.

Funding: This research was funded by the National Natural Science Foundation of China (Grant No. 51574201) and the Scientific and Technical Youth Innovation Group (Southwest Petroleum University) (2015CXTD05).

Conflicts of Interest: The authors declare no conflict of interest.

\section{References}

1. Marek, L.; Miřijovský, J.; Tuček, P. Monitoring of the Shallow Landslide Using UAV Photogrammetry and Geodetic Measurements. In Engineering Geology for Society and Territory; Springer: Berlin, Germany, 2015; Volume 2, pp. 113-116.

2. Benoit, L.; Briole, P.; Martin, O.; Thom, C.; Malet, J.P.; Ulrich, P. Monitoring landslide displacements with the Geocube wireless network of low-cost GPS. Eng. Geol. 2015, 195, 111-121. [CrossRef]

3. China National Standards. GB 50026-2007, Code for Engineering Surveying; China Planning Press: Shenzhen, China, 2008; p. 8.

4. Abellán, A.; Oppikofer, T.; Jaboyedoff, M.; Rosser, N.J.; Lim, M.; Lato, M.J. Terrestrial laser scanning of rock slope instabilities. Earth Surf. Process. Landf. 2014, 39, 80-97. [CrossRef]

5. Sun, Q.; Zhang, L.; Ding, X.L.; Hu, J.; Li, Z.W.; Zhu, J.J. Slope deformation prior to Zhouqu, China landslide from InSAR time series analysis. Remote Sens. Environ. 2015, 156, 45-57. [CrossRef]

6. Feng, D.; Feng, M.Q.; Ozer, E.; Fukuda, Y. A Vision-Based Sensor for Noncontact Structural Displacement Measurement. Sensors 2015, 15, 16557-16575. [CrossRef] [PubMed]

7. Yoon, H.; Elanwar, H.; Choi, H.; Golparvar-Fard, M.; Spencer, B.F. Target-free approach for vision-based structural system identification using consumer-grade cameras. Struct. Control Health Monit. 2016, 23, 1405-1416. [CrossRef]

8. Khuc, T.; Catbas, F.N. Completely contactless structural health monitoring of real-life structures using cameras and computer vision. J. Int. Assoc. Struct. Control Monit. 2017, 24. [CrossRef]

9. Harris, C.; Stephens, M. A Combined Corner and Edge Detector. Proc. Alvey Vis. Conf. 1988, 1988, $147-151$.

10. Bay, H.; Ess, A.; Tuytelaars, T.; Gool, L.V. Speeded-Up Robust Features (SURF). Comput. Vis. Image Understand. 2008, 110, 346-359. [CrossRef]

11. Chang, C.C.; Ji, Y.F. Flexible Videogrammetric Technique for Three-Dimensional Structural Vibration Measurement. J. Eng. Mech. 2007, 133, 656-664. [CrossRef] 
12. Choi, I.; Kim, J.; Kim, D. A Target-Less Vision-Based Displacement Sensor Based on Image Convex Hull Optimization for Measuring the Dynamic Response of Building Structures. Sensors 2016, 16, 2085. [CrossRef] [PubMed]

13. Hu, Q.; He, S.; Wang, S.; Liu, Y.; Zhang, Z.; He, L.; Wang, F.; Cai, Q.; Shi, R.; Yang, Y. A High-Speed Target-Free Vision-Based Sensor for Bus Rapid Transit Viaduct Vibration Measurements Using CMT and ORB Algorithms. Sensors 2017, 17, 1305. [CrossRef] [PubMed]

14. Feng, D.; Feng, M.Q. Experimental validation of cost-effective vision-based structural health monitoring. Mech. Syst. Signal Process. 2017, 88, 199-211. [CrossRef]

15. Choi, H.S.; Cheung, J.H.; Kim, S.H.; Ahn, J.H. Structural dynamic displacement vision system using digital image processing. NDT E Int. 2011, 44, 597-608. [CrossRef]

16. Song, Y.Z.; Bowen, C.R.; Kim, A.H.; Nassehi, A.; Padget, J.; Gathercole, N. Virtual visual sensors and their application in structural health monitoring. Struct. Health Monit. 2014, 13, 251-264. [CrossRef]

17. Zhao, X.; Liu, H.; Yu, Y.; Xu, X.; Hu, W.; Li, M.; Ou, J. Bridge displacement monitoring method based on laser projection-sensing technology. Sensors 2015, 15, 8444-8463. [CrossRef] [PubMed]

18. Jeon, H.; Kim, Y.; Lee, D.; Myung, H. Vision-Based Remote 6-DOF Structural Displacement Monitoring System Using a Unique Marker. Smart Struct. Syst. 2014, 13, 927-942. [CrossRef]

19. Shariati, A.; Schumacher, T. Eulerian-based virtual visual sensors to measure dynamic displacements of structures. Struct. Control Health Monit. 2017, 24, e1977. [CrossRef]

20. Feng, D.; Feng, M.Q. Vision-based multipoint displacement measurement for structural health monitoring. Struct. Control Health Monit. 2016, 23, 876-890. [CrossRef]

21. Ye, X.W.; Yi, T.H.; Dong, C.Z.; Liu, T. Vision-based structural displacement measurement: System performance evaluation and influence factor analysis. Measurement 2016, 88, 372-384. [CrossRef]

22. Lee, H.; Rhee, H.; Oh, J.H.; Jin, H.P. Measurement of 3-D Vibrational Motion by Dynamic Photogrammetry Using Least-Square Image Matching for Sub-Pixel Targeting to Improve Accuracy. Sensors 2016, 16, 359. [CrossRef] [PubMed]

23. Xu, W.; Li, Q.; Feng, H.J.; Xu, Z.H.; Chen, Y.T. A novel star image thresholding method for effective segmentation and centroid statistics. Optik Int. J. Light Electron Opt. 2013, 124, 4673-4677. [CrossRef]

24. Weng, M.; He, M. Image detection based on SUSAN method and integrated feature matching. Int. J. Innov. Comput. Inf. Control Ijicic 2008, 4, 671-680.

25. Hollitt, C. A convolution approach to the circle Hough transform for arbitrary radius. Mach. Vis. Appl. 2013, 24, 683-694. [CrossRef]

26. Shi, J.; Tomasi, C. Good features to track. In Proceedings of the IEEE Conference on Computer Vision and Pattern Recognition (CVPR'94), Seattle, WA, USA, 21-23 June 1994.

27. Danelljan, M.; Khan, F.S.; Felsberg, M.; Weijer, J.V.D. Adaptive Color Attributes for Real-Time Visual Tracking. In Proceedings of the IEEE Conference on Computer Vision and Pattern Recognition, Beijing, China, 23-28 June 2014; pp. 1090-1097.

28. Henriques, J.F.; Rui, C.; Martins, P.; Batista, J. High-Speed Tracking with Kernelized Correlation Filters. IEEE Trans. Pattern Anal. Mach. Intell. 2015, 37, 583-596. [CrossRef] [PubMed]

29. Zhang, K.; Zhang, L.; Yang, M.H. Real-time object tracking via online discriminative feature selection. IEEE Trans. Image Process. 2013, 22, 4664-4677. [CrossRef] [PubMed]

30. Zhang, K.; Zhang, L.; Liu, Q.; Zhang, D.; Yang, M.H. Fast Visual Tracking via Dense Spatio-temporal Context Learning. In Proceedings of the 13th European Conference on Computer vision (ECCV), Zurich, Switzerland, 6-12 September 2014; Volume 8693, pp. 127-141.

31. Zhang, K.; Zhang, L.; Yang, M.H.; Zhang, D. Fast Tracking via Spatio-Temporal Context Learning. arXiv, 2013, arXiv:1311.1939.

32. Molinaviedma, A.J.; Felipesesé, L.; Lópezalba, E.; Díaz, F. High frequency mode shapes characterisation using Digital Image Correlation and phase-based motion magnification. Mech. Syst. Signal Process. 2018, 102, 245-261. [CrossRef]

33. Javh, J.; Slavič, J.; Boltežar, M. High frequency modal identification on noisy high-speed camera data. Mech. Syst. Signal Process. 2018, 98, 344-351. [CrossRef]

34. Javh, J.; Slavič, J.; Boltežar, M. The subpixel resolution of optical-flow-based modal analysis. Mech. Syst. Signal Process. 2017, 88, 89-99. [CrossRef] 
35. Xu, Y.; Brownjohn, J.; Kong, D. A non-contact vision-based system for multipoint displacement monitoring in a cable-stayed footbridge. Struct. Control Health Monit. 2018, 25, e2155. [CrossRef]

36. Guizar-Sicairos, M.; Thurman, S.T.; Fienup, J.R. Efficient subpixel image registration algorithms. Opt. Lett. 2008, 33, 156. [CrossRef] [PubMed]

37. Zhang, G. Vision Measurement; Science Press: Beijing, China, 2008; pp. 144-148. (In Chinese)

38. Gao, S.Y. Improved Algorithm about Subpixel Edge Detection of Image Based on Zernike Orthogonal Moments. Acta Autom. Sin. 2008, 34, 1163-1168. [CrossRef]

39. Gander, W.; Golub, G.H.; Strebel, R. Least-Squares Fitting of Circles and Ellipses. BIT Numer. Math. 1994, 34, 558-578. [CrossRef]

40. Zhang, H.; Yu, H.; Li, Y.; Hu, B. Improved K-means Algorithm Based on the Clustering Reliability Analysis. In Proceedings of the International Symposium on Computers and Informatics, Beijing, China, 17-18 January 2015.

41. Sun, S.-G.; Wang, C.; Zhao, J.; Destech Publicat, I. The Application of Improved GM $(1,1)$ Model in Deformation Prediction of Slope. In Proceedings of the 2nd International Conference on Sustainable Energy and Environmental Engineering, Xiamen, China, 18-19 December 2016.

42. Zhang, Z. A Flexible New Technique for Camera Calibration; IEEE Computer Society: Washington, DC, USA, 2000; pp. 1330-1334.

(c) 2018 by the authors. Licensee MDPI, Basel, Switzerland. This article is an open access article distributed under the terms and conditions of the Creative Commons Attribution (CC BY) license (http://creativecommons.org/licenses/by/4.0/). 